\title{
Publisher Correction: Photoelectrocatalytic $\mathrm{C}-\mathrm{H}$ halogenation over an oxygen vacancy-rich $\mathrm{TiO}_{2}$ photoanode
}

Zhenhua Li (D), Lan Luo, Min Li, Wangsong Chen, Yuguang Liu, Jiangrong Yang, Si-Min Xu(D, Hua Zhou (1), Lina Ma, Ming Xu, Xianggui Kong \& Haohong Duan (B)

Correction to: Nature Communications https://doi.org/10.1038/s41467-021-26997-z, published online 18 November 2021.

The original version of this Article contained an error in Fig. 2, in which two curved arrows were inadvertently omitted. The correct version of Fig. 2 is:
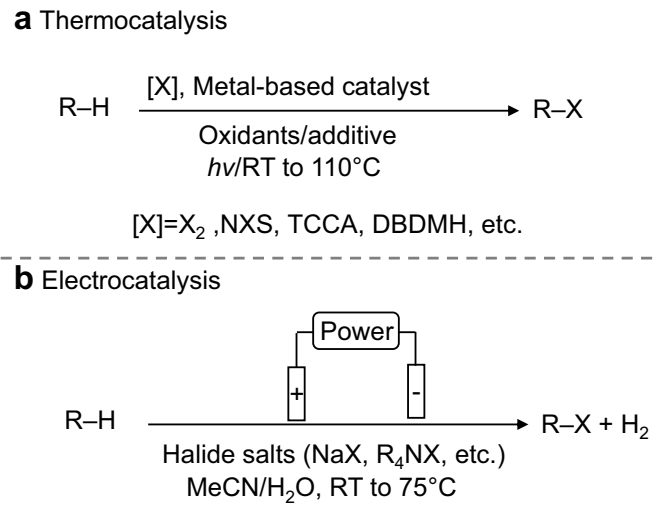

C PEC (this work)

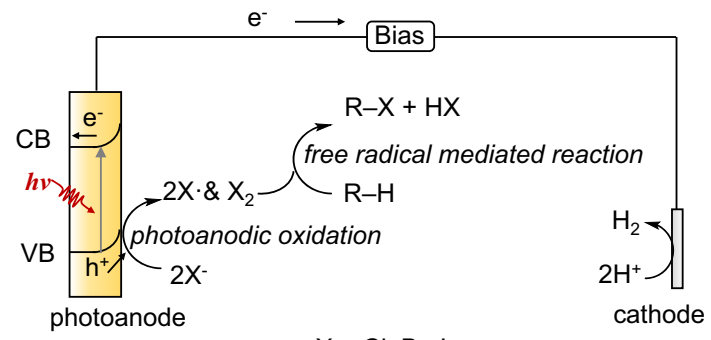

$\mathrm{X}=\mathrm{Cl}, \mathrm{Br}, \mathrm{I}$

Fig. 2

which replaces the previous incorrect version: 
a Thermocatalysis

$$
\begin{gathered}
\mathrm{R}-\mathrm{H} \quad \stackrel{[\mathrm{X}], \text { Metal-based catalyst }}{\begin{array}{c}
\text { Oxidants/additive } \\
h v / \mathrm{RT} \text { to } 110^{\circ} \mathrm{C}
\end{array}} \mathrm{R}-\mathrm{X} \\
{[\mathrm{X}]=\mathrm{X}_{2}, \mathrm{NXS}, \mathrm{TCCA}, \mathrm{DBDMH}, \text { etc. }}
\end{gathered}
$$

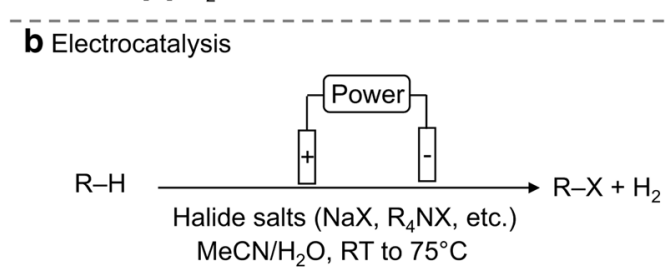

C PEC (this work)

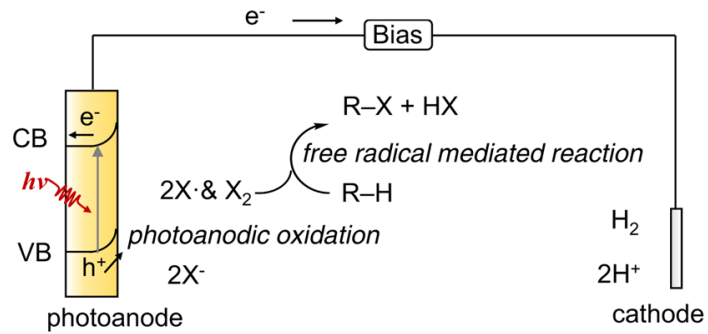

$\mathrm{X}=\mathrm{Cl}, \mathrm{Br}, \mathrm{I}$

Fig. 2

This has been corrected in both the PDF and HTML versions of the Article.

The original version of this Article contained errors in Equations (B), (C), (E), (G), (H) and (I). In Equation (B), the 1 of $\mathrm{Cl}$ was superscripted and a hyphen was not superscripted, and incorrectly read: $\mathrm{Cl}^{-} * \rightarrow \mathrm{C}^{\mathrm{l}} *+e-$. The correct form of Equation (B) is: $\mathrm{Cl}^{-*} \rightarrow \mathrm{Cl}^{*}+\mathrm{e}^{-}$.

In Equation (C), a dot was omitted, and incorrectly read: $\mathrm{Cl}^{*} \rightarrow^{*}+\mathrm{Cl}$ The correct form of Equation $(\mathrm{C})$ is: $\mathrm{Cl}^{*} \rightarrow{ }^{*}+\mathrm{Cl}$.

In Equation (E), the 1 of $\mathrm{Cl}$ was superscripted, and incorrectly read: $\mathrm{Cl}^{*} \rightarrow \mathrm{C}^{*}+\mathrm{e}^{-}$. The correct form of Equation (E) is: $\mathrm{Cl}^{*} \rightarrow \mathrm{Cl}^{*}+\mathrm{e}^{-}$.

In Equation $(\mathrm{G})$, a space was added, and incorrectly read: $\mathrm{Cl} \cdot+\mathrm{Cl} \cdot \rightarrow \mathrm{Cl}_{2}$ (in solvent). The correct form of Equation ( $\left.\mathrm{G}\right)$ is: $\mathrm{Cl} \cdot+\mathrm{Cl} \cdot \rightarrow \mathrm{Cl}_{2}$ (in solvent).

In Equation $(\mathrm{H})$, a 2 was not subscripted, and incorrectly read: $\mathrm{Cl}_{2} \rightarrow^{*}+\mathrm{Cl}_{2}$. The correct form of Equation $(\mathrm{H})$ is: $\mathrm{Cl}_{2}{ }^{*} \rightarrow{ }^{*}+\mathrm{Cl}_{2}$.

In Equation (I), a space was added and a 6 was not subscripted, and incorrectly read: $\mathrm{Cl} \cdot+\mathrm{C}_{6} \mathrm{H}_{12} \rightarrow \mathrm{C} 6 \mathrm{H}_{11} \cdot+\mathrm{HCl}$. The correct form of Equation (I) is: $\mathrm{Cl} \cdot+\mathrm{C}_{6} \mathrm{H}_{12} \rightarrow \mathrm{C}_{6} \mathrm{H}_{11} \cdot+\mathrm{HCl}$.

This has been corrected in the PDF and HTML versions of the Article.

Published online: 16 December 2021

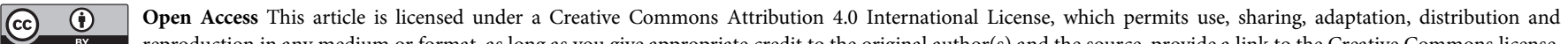
and indicate if changes were made. The images or other third party material in this article are included in the article's Creative Commons license, unless indicated otherwise in a credit line to the material. If material is not included in the article's Creative Commons license and your intended use is not permitted by statutory regulation or exceeds the permitted use, you will need to obtain permission directly from the copyright holder. To view a copy of this license, visit http://creativecommons.org/licenses/by/4.0/.

(c) The Author(s) 2021 